\title{
Evolution of the Z-Scheme of Electron Transport in Oxygenic Photosynthesis
}

\author{
Govindjee $^{\mathrm{a} *}$, Lars Olof Björn ${ }^{\mathrm{b}, \mathrm{c}}$, Kärin Nickelsen ${ }^{\mathrm{d}}$ \\ a'Biochemistry, Biophysics and Plant Biology, University of Illinois, 265 Morrill Hall, 505 South Goodwin Avenue, Urbana, IL 61801,USA; \\ ${ }^{\mathrm{b}}$ School of Life Science, South China Normal University, Guangzhou, China; \\ ${ }^{\mathrm{c}}$ Department of Biology, Lund University, Lund, Sweden; \\ ${ }^{\mathrm{d}}$ History and Philosophy of Science, Bern University, Bern, Switzerland. \\ *Corresponding author. Tel. No. 217-337-0627; Fax No. 217-244-7246; E-mail: gov@life.illinois.edu.
}

\begin{abstract}
We start with the discussion of the photosynthetic unit, based on the experiments of Emerson and Arnold (1932a, 1932b), continue with the first two-quantum proposal by Rabinowitch (1945, 1956), Emerson's Red drop (1943) and Emerson Enhancement Effect (1957) and various action spectra made for understanding the roles of the photosynthetic pigments. The experimental work of Kok (1959) and the theoretical model by Hill and Bendall (1960) were followed soon thereafter by the seminal papers of Duysens et al. (1961) and Duysens and Amesz (1962), in which the two photosystems were shown to be connected, in series, by cytochrome, which can be photooxidized by photo system I and photoreduced by photosystem II. Further, Witt et al. (1961) and others, cited in this paper, made refinement of the Z-scheme.
\end{abstract}

Keywords: Electron transport; Photosynthetic unit; Photosynthesis; Photosystem; Z-scheme

\section{Introduction}

Today, the Z-scheme of the so-called light reactions of photosynthesis is part of the common knowledge. It is published and proliferated in different degrees of detail, ranging from very rough sketches of the zig-zag pattern to detailed elaboration of the participating molecules. It was, however, a long way to get there. In this paper we provide a brief overview of the path that, eventually, led to today's two light reaction two photosystem account of the electron transport path from water to NADP in photosynthesis (See Govindjee and Björn, 2011; Nickelsen, 2010).

\section{The Photosynthetic Unit}

Emerson and Arnold (1932a, 1932b) separated and characterized the "light reaction" and the "dark reaction" of photosynthesis. They delivered very short and intense repetitive light flashes, and studied how photosynthesis in the green alga Chlorella changed when intensity, flash duration, and flash interval were varied. They postulated the existence of "photosynthetic units" which were activated by the light flashes, and during the intervening dark periods completed photosynthesis by carrying out the "dark reaction". They found that the maximum amount of oxygen released per flash, under optimum dark and light conditions, was one oxygen molecule per $\sim 2,400$ molecules of chlorophyll: "We need only suppose that for every 2480 molecules of chlorophyll there is present in the cell one unit capable of reducing one molecule of carbon dioxide each time it is suitably activated by light." However, it was in Gaffron and Wohl (1936) that the concept of the "unit", in which energy is transferred between pigment molecules, was elaborated. In later years, it became apparent that different organisms have units of different size, so that the number of 2,400 was by no means universal. Schmid and Gaffron (1968) showed that in several algae, cyanobacteria and higher plants, the number of chlorophyll molecules evolved per oxygen, under different physiological conditions, was in multiples of 300: 300, 600, 1,200, 1,800, 2,400 and even $\sim 4,800$. 


\section{Quantum yields}

The Stark-Einstein equivalence law (see Einstein, 1912) states that one photon reacts with one molecule. Until late in the 1930s, the role of light in photosynthesis was conceived of as splitting $\mathrm{CO}_{2}$ into $\mathrm{O}_{2}$ and activated carbon (the light reaction), which then would react with water to yield carbohydrate (the dark reaction). A simplistic application of the StarkEinstein equivalence law to this would require one photon per $\mathrm{CO}_{2}$ consumed or $\mathrm{O}_{2}$ released. We now know that this theory is incorrect; the $\mathrm{O}_{2}$ comes from water (Fig. 1).

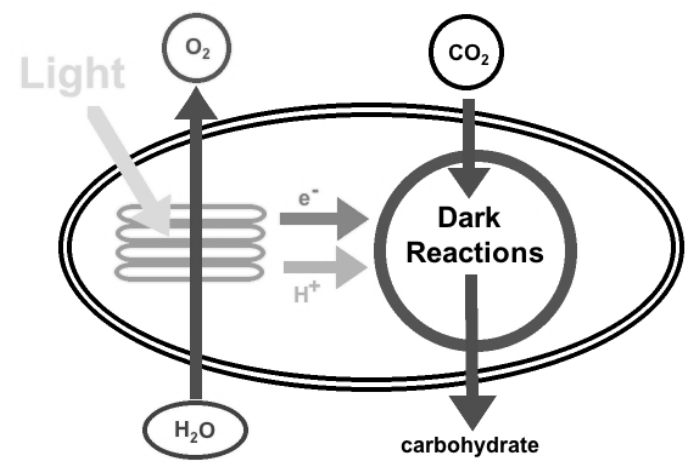

Fig. 1 A very simplified diagram of photosynthesis, showing that, in the thylakoids, light is used to convert water into molecular oxygen, electrons and protons, and, in the stroma outside the thylakoids these electrons and protons are used to make carbohydrate from carbon dioxide.

The oxidation of two water molecules to yield one oxygen molecule requires removal of 4 electrons and 4 protons, and it is natural to assume that movement of one electron or proton requires one photon. However, this was not always common sense. The experimental determination of minimum quantum requirement for photosynthesis gave, in fact, rise to one of the greatest controversies in the history of photosynthesis research. Determining this requirement was, at the time, a way to exclude certain photosynthesis theories, which were in disagreement with the energy budget. The great German biochemist Otto Warburg, who was already famous for his research on respiration enzymes, argued for a minimum quantum requirement of 4 , in accordance with the one-electron-one-photon principle (Warburg and Negelein, 1923; Warburg et al., 1950; Warburg, 1958). He even eventually found a requirement of only 3 photons per oxygen evolved, and elaborated a theory to explain this. In contrast to this, Emerson and
Lewis (1941, 1943) found a minimum quantum requirement of 10-12 photons per oxygen molecule evolved or carbon dioxide molecule absorbed. Since the experiments were highly intricate, it was far from easy to resolve this disagreement. In a final paper, Warburg et al. (1969) published experimental results in agreement with the value of 12 photons per oxygen, but still interpreted them, wrongly, in our opinion, as 3 photons per oxygen molecule (Govindjee, 1999). In a long series of experiments, Yuan et al. (1955) obtained requirements of $8.7 \pm 1.0$ photons per molecule of carbon dioxide assimilated, and $9.1 \pm 1.1$ photons per molecule of oxygen evolved. Even more importantly, Rajni Govindjee et al. (1968) demonstrated that the minimum quantum requirement for cultures of Chlorella, which were grown under conditions specified by Warburg, was 8-12.

\section{Eugene Rabinowitch's 2-step photosynthesis scheme}

In parallel to the experiments on photosynthetic quantum yields, attempts were made to spell out the biochemical (and biophysical) mechanism of photosynthesis. Eugene Rabinowitch (1945) discussed the first theory with two photochemical reactions in series in the first volume of his photosynthesis monograph. In this scheme (Fig. 2) the reaction HZ to $\mathrm{Z}$ corresponds to what we now call Photosystem II, and HY to Y corresponds to Photosystem I. The nature of $\mathrm{X}, \mathrm{Y}$ and $\mathrm{Z}$ remained unknown. But already in the second volume of his monograph, Rabinowitch (1956) hinted at cytochrome as the intermediate electron carrier $\mathrm{Y}$. The reason for this was the reversible oxidation of cytochrome $f$ by light that had been discovered by Duysens (1955) and Lundegårdh (1954). Rabinowitch (1956) wrote:"...photochemical transfer of electrons from reduced cytochrome to the organic acceptor (perhaps via DPN or TPN). The transfer of hydrogen (or electrons) from $\mathrm{H}_{2} \mathrm{O}$ to the oxidized cytochrome would then require another photochemical reaction." and "The quantum requirement of the hydrogen transfer reaction as a whole would be (at least) 8 , since two quanta will be needed to transfer each of the four required $H$ atoms (or electrons), first from water to the cytochrome, and then from the cytochrome to the final acceptor." (DPN and TPN were the acronyms used in those days for what we now call NAD and NADP.) 


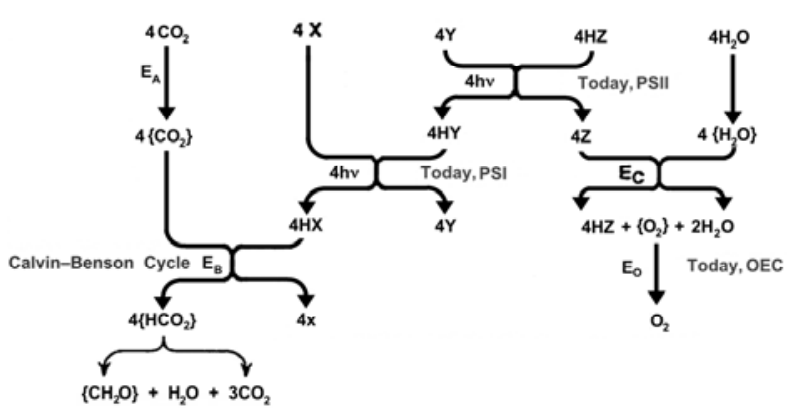

Fig. 2 A 1945 two-photoreaction scheme for photosynthesis (Rabinowitch, 1945; Modified by Govindjee; reproduced with his permission), with PSI, PSII, and OEC (oxygen evolving complex) added by the authors.

\section{Spectral light effects: Blinks Effect and Emerson Enhancement Effect}

Blinks $(1957,1960)$ observed strange transients in oxygen evolution, first in red algae, and later also in other algae. Even if intensities of red and green light were adjusted to give the same photosynthesis rate with each light, changes in photosynthesis rate were observed when switching from one to the other. This showed that the two kinds of light had different effects, or, in other words, were driving different reactions (while the latter was not immediately clear to Blinks); in fact, Blinks (1960) considered his effects to be due to changes in respiration.

Already in the early 1940s, Emerson and Lewis (1943) had found that the quantum yield for photosynthesis by Chlorella varied with wavelength. Lower yield in the blue-violet region could readily be explained by the presence of yellow pigments that did not "collect" all of its light for photosynthesis. In the yellow to red part of the spectrum the yield was higher and fairly constant up to about $680 \mathrm{~nm}$, but at higher wavelengths it dropped very steeply, although the chlorophyll was still absorbing. Much later, Emerson and coworkers (Emerson et al., 1957; Emerson and Chalmers, 1958; cf. Emerson and Rabinowitch, 1960) discovered that a background of light of shorter wavelength could counteract this "red drop". This became known as the "(Emerson) Enhancement Effect" of photosynthesis. Warburg et al. (1954) had earlier studied the effect of combining blue "catalytic" light, with red light but this experiment as well as its conclusion is not relevant to the Emerson Enhancement effect except that it might have given ideas to Emerson to use two light beams in his experiments.
Emerson and Chalmers (1958) brought forward the suggestion that there were, in fact, two light reactions in photosynthesis, while they proposed that one of them was sensitized by chlorophyll $a$ and the other by chlorophyll $b$ or other accessory pigments see also Myers and French (1960). However, Govindjee and Rabinowitch (1960) and R. Govindjee et al. (1960) showed that a short wavelength absorbing form of chlorophyll $a$ was present in the same system that used chlorophyll $b$ (or other accessory pigments). This agreed with the earlier observations of Duysens (1952) that all energy absorbed by chlorophyll $b$ is transferred to chlorophyll $a$. Further, Govindjee et al. (1960) discovered a corresponding effect on chlorophyll $a$ fluorescence from Chlorella cells: light absorbed in the "red drop" region quenched chlorophyll $a$ fluorescence excited by high intensity short wavelength light. This phenomenon was thoroughly explored by Duysens and Sweers (1963) leading to an establishment of the relationship of two light reactions and two pigment systems with chlorophyll fluorescence.

\section{The Z-scheme: Contributions of Kok, Duysens, Hill and their coworkers}

Around 1960 all of the previously somewhat perplexing experimental results had a consistent explanation. Several almost simultaneous publications contributed to this: this is a clear indication of the fact that the solution was, so to speak, "in the air".

Kok (1959), in the Robert Emerson Memorial issue of Plant Physiology, showed a two-light effect (in a cyanobacterium Anacystis nidulans) on the redox state of a special chlorophyll which he had earlier dubbed "P700": the pigment was oxidized when illuminated by a long wavelength light (far-red), while the oxidized P700 was reduced when a short wavelength light (orange-red) was added. Kok explicitly related these findings to the Emerson Enhancement Effect (see also Kok and Hoch, 1961 for a more detailed presentation).

Around the same time, Duysens examined the action spectra for cytochrome oxidation and $\mathrm{NADP}^{+}$ reduction in different wavelengths of light, and in August1960, he presented his results at the $3^{\text {rd }}$ International Congress on Photobiology at Copenhagen, Denmark. Duysens was able to show that in the red alga Porphyridium, green light, 
absorbed by phycoerythrin, gave a low yield of cytochrome oxidation when the photosynthetic yield was high, but a high yield of cytochrome oxidation in red light, absorbed by chlorophyll a, when the photosynthetic yield was low. Based on these observations, Duysens postulated the existence of two Photosystems, 1 and 2. (At that time, he was unaware of the paper of Hill and Bendall, 1960). Duysens (1989) wrote, retrospectively, about his earlier work: "System 1 contained the weakly fluorescent chlorophyll a, formerly said to be inactive, and oxidized cytochrome; system 2 contained the fluorescent chlorophyll a. An interaction between the two systems was shown by the different kinetics of cytochrome oxidation at different actinic wavelengths."

The fact that there were different types of chlorophyll $a$, which had distinct functions in the photosynthetic process in Chlorella cells, was first brought up in Govindjee and Rabinowitch (1960) and elaborated in Rabinowitch and Govindjee (1961). French (1961) had independently come to the same conclusion. In March 1960, Rabinowitch and Govindjee stated, in view of their findings: "the primary photochemical process in photosynthesis might consist of two steps: whereas one type of chlorophyll a was able to bring about both, the other type was restricted to one of these steps."

The key experiment for demonstrating the existence of two light reactions was published by Duysens et al. (1961) (see also Duysens and Amesz, 1962): light of wavelengths attributed by the authors to system 1 (light 1) oxidized a cytochrome, while light of wavelengths attributed to system 2 (light 2) reduced it. This was the discovery of the antagonistic effect of light 1 and 2 on an intermediate that was predicted by Rabinowitch (1956) and is still the best experimental evidence for the series scheme of photosynthesis. Further, Duysens et al. (1961) showed that in the presence of diuron (DCMU), cytochrome can be oxidized, but not reduced.

The paper of Hill and Bendall (1960), published during this period, is a landmark in the study of the "light reactions" of photosynthesis. Hill and Bendall addressed the problem from the point of view of thermodynamics. Already in the 1950s, two plantspecific cytochromes had been found in chloroplasts (Hill and Scarisbrick, 1951; Davenport and Hill, 1952).The possibility that cytochromes might be the elements to link two photosystems and provided energy for the formation of ATP through a downhill step between the two cytochromes was clearly the novel concept in the Robert (Robin) Hill and Fay Bendall scheme — while they missed, unintentionally, we believe, citing the pioneering work of Robert Emerson, which was mentioned earlier. Due to the graphical representation of this scheme, which was adopted in later years, it became known as the " $\mathrm{Z}$ scheme" of photosynthesis.

The most precise biophysical measurements of the absorption changes were by Witt, Müller and Rumberg (1961a, 1961b); they used flashing light spectroscopic methods, which greatly increased the sensitivity and the time resolution of photosynthesis studies. Based on this technique, Witt et al. (1961a, 1961b) found that (1) upon excitation with light $(710 \mathrm{~nm})$ cytochrome $f$ was oxidized and stayed in this state for seconds; (2) after excitation with light 2 $(670 \mathrm{~nm})$ an unidentified component $\mathrm{X}$ was oxidized to XO. From these findings, they concluded (at almost the same time as Kok and Hoch as well as Duysens and coworkers) "that photosynthesis is triggered by two different photochemical reactions: oxidation of cytochrome by Chla-680 and reduction of XO by Chla-670". Witt et al. (1961a, 1961b) additionally suggested that the reaction $\mathrm{XO} \rightarrow \mathrm{X}$ might be the reaction of plastoquinone to hydroquinone (see also the retrospective discussion of this work by Witt (1991)).

Losada et al. (1961) from Daniel Arnon's laboratory provided one of the first biochemical measurements supporting the "Z-Scheme". However, Daniel Arnon soon abandoned this scheme in favor of a 3-light reaction scheme, or a 2-light light scheme, both run by two types of Photosystem II and even a one light reaction scheme. We shall not discuss them here. By 1963, the major concepts and experiments on the two light- reaction and two-pigment scheme had been settled (see Kok and Jagendorf, 1963). The two light reaction, two pigment system scheme was further supported by the physical separation of the two photosystems (see e.g., Boardman and Anderson, 1964; Anderson, 2005), by 'chemical surgery' of the entire scheme and by the use of specific inhibitors, artificial donors and acceptors of partial reactions (see e.g., reviews by Vernon and Avron (1965) and Trebst (1974), and through the use of mutants that lacked specific intermediates in the electron transport chain (see e.g., Gorman and Levine, 1966; see Levine, 1969, for a review). 


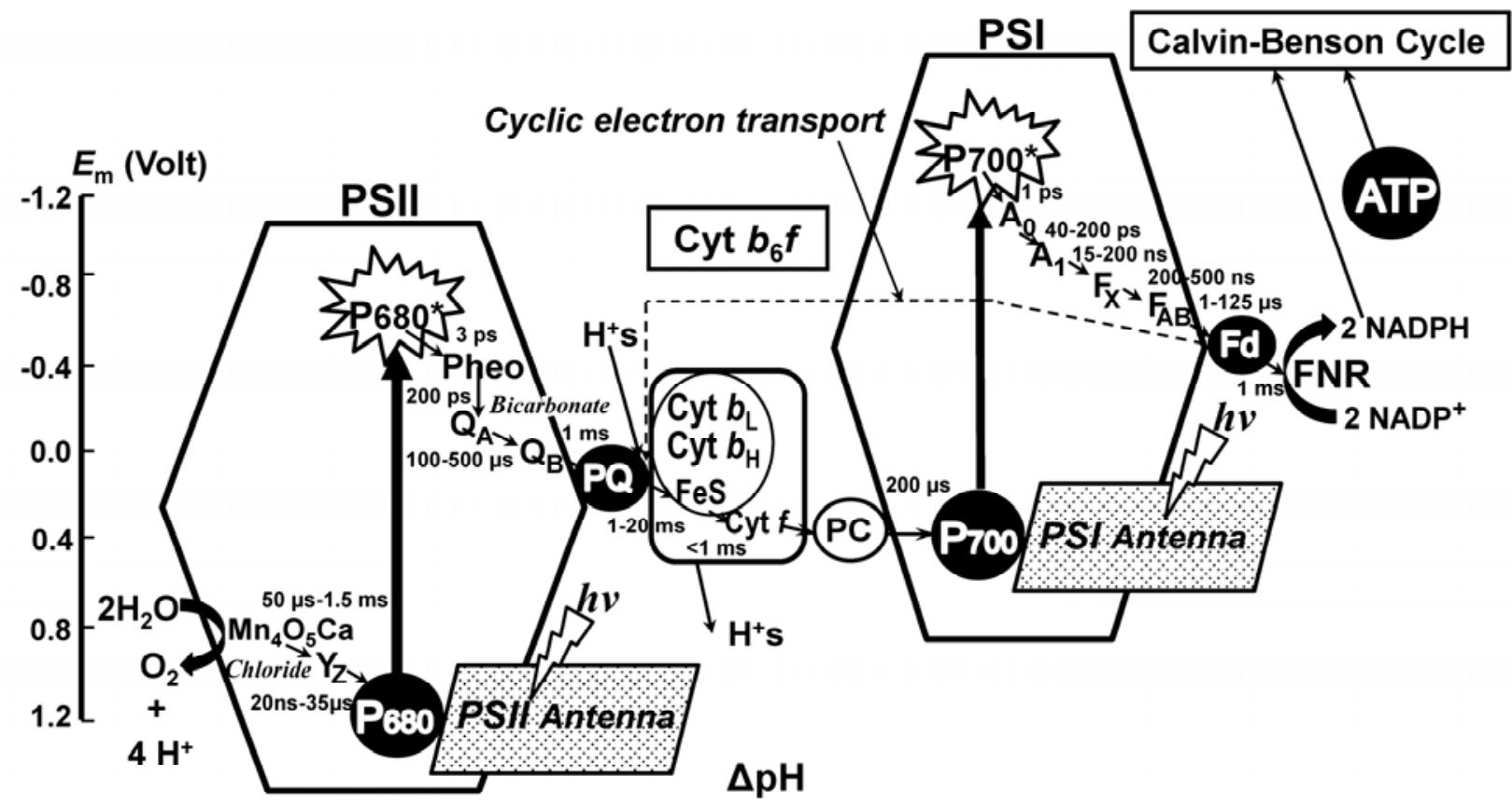

Fig. 3 A current Z-Scheme for electron transport (Stirbet and Govindjee, 2011; courtesy of Alexandrina Stirbet; Reproduced with the permission from AStirbet and Govindjee).

\section{The current scheme}

We conclude this paper by showing a selected current scheme (Fig. 3) that is used to describe the process of the photosynthetic "light reactions". Other available schemes range from a bunch of circles to a chair-like structure, from zig-zag (or Z-) shaped graphs to a slightly distorted $\mathrm{N}$.

\section{References}

Anderson J (2005) Changing Concepts about the Distribution of Photosystems I and II between Grana-Appressed and Stroma-Exposed Thylakoid Membranes. In: Govindjee, Beatty JT, Gest H, Allen JF (eds.), Discoveries in Photosynthesis. Springer: Dordrecht, pp. 729-736

Blinks LR (1957) Chromatic Transient in Photosynthesis of Red Algae. In: Gaffron H, Brown AH, French CS, Livingston R, Rabinowitch EI, Strehler B, Tolbert NE (eds.), Research in Photosynthesis. Interscience Publishers: New York, pp. 444-449

Blinks LR (1960) Relation of Photosynthetic Transients to Respiration. Science 131: 1316
Boardman NK, Anderson JM (1964) Isolation from Spinach Chloroplasts of Particles Containing Different Proportions of Chlorophyll a and Chlorophyll b and Their Possible Role in Light Reactions of Photosynthesis. Nature 203: 166-167. Davenport HE, Hill R (1952) The Preparation and Some Properties of Cytochrome f. Proc. Royal Soc. London Series B 139: 327-345

Duysens LNM (1952) Transfer of Excitation Energy in Photosynthesis. Doctoral Thesis. State University, Utrecht, The Netherlands

Duysens LNM (1955) Role of Cytochrome and Pyridine Nucleotide in Algal Photosynthesis. Science 121: 210- 211

Duysens LNM (1989) The Discovery of the Two Photosynthetic Systems: a Personal Account. Photosynth. Res. 21: 61-80

Duysens LNM, Amesz J (1962) Function and Identification of Two Photochemical Systems in Photosynthesis. Biochim. Biophys. Acta 64: 243260

Duysens LNM, Sweers HE (1963) Mechanism of Two Photochemical Reactions in Algae As Studied by Means of Fluorescence. In: Japanese Society of Plant Physiologists (eds.), Studies on Microalgae and Photosynthetic Bacteria. University of Tokyo Press: Tokyo, pp. 353-372 
Duysens LNM, Amesz J, Kamp BM (1961) Two Photochemical Systems in Photosynthesis. Nature 190: 510-511

Einstein A (1912) Thermodynamische Begründung des Photochemischen Äquivalentgesetzes. Ann. Phys. 14 (Suppl): 437-443

Emerson R, Arnold W (1932a) A Separation of the Reactions in Photosynthesis by Means of Intermittent Light. J. Gen. Physiol. 15: 391-420

Emerson R, Arnold W (1932b) The Photochemical Reaction in Photosynthesis. J Gen Physiol 16: 191-205

Emerson R, Chalmers RV (1958) Speculations Concerning the Function and Phylogenetic Significance of the Accessory Pigments of Algae. Phycol. Soc. News Bull. 11: 51-56

Emerson R, Lewis CM (1941) Carbon Dioxide Exchange and Measurement of the Quantum Yield of Photosynthesis. Am. J. Bot. 28: 789-804

Emerson R, Lewis CM (1943) The Dependence of the Quantum Yield of Chlorella Photosynthesis on Wavelength of Light. Am. J. Bot. 30: 165-178

Emerson R, Rabinowitch E (1960) Red Drop and Role of Auxiliary Pigments in Photosynthesis. Plant Physiol. 35: 477-485

Emerson R, Chalmers RV, Cederstrand CN (1957) Some Factors Influencing the Long-Wave Limit of Photo-Synthesis. Proc. Natl. Acad. Sci. USA 43: $133-143$

French CS (1961) Light, Pigments and Photosynthesis. In: McElroy WD, Glass B (eds.), Light and Life.The Johns Hopkins Press: Baltimore, pp. 447-474

Gaffron H, Wohl K (1936) Zur Theorie der Assimilation. Naturwissenschaften 24: 81-90; 103-107

Gorman DS, Levine RP (1966) Photosynthetic Electron Transport Chain of Chlamydomonas Reinhardtii.VI. Electron Transport in Mutant Strains Lacking either Cyt 559 or Plastocyanin. Plant Physiol. 41: 1648-1656

Govindjee (1999) On the Requirement of Minimum Number of Four Versus Eight Quanta of Light for the Evolution of One Molecule of Oxygen in Photosynthesis. Photosynth. Res. 59: 249-254

Govindjee, Björn LO (2011) Dissecting Oxygenic Photosynthesis: the Evolution of the "Z"-Scheme for Thylakoid Reactions. In: Itoh S, Mohanty P, Guruprasad KN (eds.), Photosynthesis: Current Progress and Future Perspectives. IK Publishers: New Delhi, pp. 1-27
Govindjee, Rabinowitch E (1960) Two Forms of Chlorophyll a in Vivo with Distinct Photochemical Functions. Science 132: 159-160

Govindjee, Ichimura S, Cederstrand C, Rabinowitch E (1960) Effect of Combining Far-Red Light with Shorter Wave Light in the Excitation of Fluorescence in Chlorella. Arch. Biochem. Biophys. 89: 322323

Govindjee R, Thomas JB, Rabinowitch E (1960) Second Emerson Effect in the Hill Reaction of Chlorella Cells with Quinone As Oxidant. Science 132: 421

Govindjee R, Rabinowitch E, Govindjee (1968) Maximum Quantum Yield and Action Spectrum of Photosynthesis and Fluorescence in Chlorella. Biochim. Biophys. Acta 162: 539-544

Hill R, Bendall F (1960) Function of the Cytochrome Components in Chloroplasts: a Working Hypothesis. Nature 186: 136-137

Hill R, Scarisbrick R (1951) The Haematin Compounds of Leaves. New Phytologist 50: 98-111

Kok B (1959) Light-Induced Absorption Changes in Photosynthetic Organisms. II. A Split-Beam Difference Spectrophotometer. Plant Physiol. 34: 184-192

Kok B, Hoch G (1961) Spectral Changes in Photosynthesis. In: WD McElroy, B Glass (eds.), Light and Life. The Johns Hopkins Press: Baltimore, Maryland, pp. 397-423

Kok B (Chairman), Jagendorf AT (Organizer) (1963) Photosynthetic Mechanisms of Green Plants. Publication \#1145. National Academy of SciencesNational Research Council, Washington, DC, see 'Foreword', pp. ix

Levine RP (1969) The Analysis of Photosynthesis Using Mutant Strains of Algae and Higher Plants. Annu. Rev. Plant Physiol. 20: 523-540

Losada M, Whatley FR, Arnon DI (1961) Separation of Two Light Reactions in Non-Cyclic PhotoPhosphorylation of Green Plants. Nature 190: 606-610

Lundegårdh H (1954) On the Oxidation of Cytochrome f by Light', Physiol. Plantarum 7: 375-382

Myers J, French CS (1960) Evidences from Action Spectra for a Specific Participation of Chlorophyll b in Photosynthesis. J. Gen. Physiol. 43: 723-736

Nickelsen K (2010) Of Light and Darkness-Modelling Photosynthesis 1840-1960. Habilitationschrifteingereicht der Phil.-nat. Fakultät der Universität Bern, Switzerland, see Chapters VI and VII 
Rabinowitch E (1945) Photosynthesis and Related Processes. Vol. I. Interscience Publishers, Inc.: New York 599: 162

Rabinowitch EI (1956) Photosynthesis and Related Processes, Vol. II (Part 2). Kinetics of Photosynthesis (continued); Addenda to Vol. I and Vol. II, Part 1, pp. 1211-2088. Interscience Publishers: New York, pp. 1862

Rabinowitch EI, Govindjee (1961) Different Forms of Chlorophyll a in Vivo and Their Photochemical Function. In: McElroy WD, Glass B (eds.), A Symposium on Light and Life. The Johns Hopkins Press: Baltimore, Maryland, pp. 378-391

Schmid G H, Gaffron H (1968) Photosynthetic Units. J. Gen. Physiol. 52: 212-239

Stirbet A, Govindjee (2011) On the Relation between the Kautsky Effect (Chlorophyll a Fluorescence Induction) and Photosystem II: Basics and Applications. J. Photochem. Photobiol. B Biology in the press

Trebst A (1974) Energy Conservation in Photosynthetic Electron Transport of Chloroplasts. Annu. Rev. Plant Physiol. 25: 423-458.

Vernon LP, Avron M (1965) Photosynthesis. Annu. Rev. Biochem. 34: 269-296

Warburg O (1958) Photosynthesis. Science 128: 6873
Warburg O, Negelein E (1923) Über den Einfluss der Wellenlänge auf den Energieumsatz bei der Kohlensäureassimilation. Z. Physik. Chem. 106: 191-218

Warburg O, Burk D, Schocken V, Hendricks SB (1950) The Quantum Efficiency of Photosynthesis. Biochim. Biophys. Acta 4: 335-348

Warburg O, Krippahl G, Schröder W, Buchholz W, Theel E (1954) Über die Wirkung sehr Schwachen Blaugrünen Lichts auf den Quantenbedarf der Photosynthese. Z. Naturforschg. 9b: 164-165

Warburg O, Krippahl G, Lehman A (1969) Chlorophyll Catalysis and Einstein's Law of Photochemical Equivalence in Photosynthesis. Am. J. Bot. 56: 961-971

Witt HT (1991) Functional Mechanism of Water Splitting Photosynthesis. Photosynth. Res. 29: 5577

Witt HT, Müller A, Rumberg B (1961a) Experimental Evidence for the Mechanism of Photosynthesis. Nature 191: 194-195

Witt HT, Müller A, Rumberg B (1961b) Oxidized Cytochrome and Chlorophyll in Photosynthesis. Nature 192: 967-969

Yuan EL, Evans RW, Daniels F (1955) Energy Efficiency of Photosynthesis by Chlorella. Biochim. Biophys. Acta 17: 185-193 